„ O R B IS L I N G U A R UM “, VOLUME 19， ISS UE 3

DOI: https://doi.org/10.37708/ezs.swu.bg.v19i3.2

\title{
OLD ENGLISH SWA SIMILES: STRUCTURE OVERVIEW
}

\author{
Mariana OLENIAK \\ Vasyl` Stus Donetsk National University, Ukraine \\ E-mail: maryana@mail.org
}

\begin{abstract}
This paper describes a way of expressing figurative similarity through Old English constructions employing the element swa 'as' (or its variants) as a comparison marker, which in early Middle English developed into two distinct lexemes: the adverb also and the conjunction as, the latter often found in clauses of comparison. The uniqueness of this type of Anglo-Saxon simile is its capability to create similes whose tenors and vehicles either nominate the referents standing behind them or provide a certain amount of information concerning their actions or states, being expressed either by lexemes or clauses, correspondingly. The constructions in question are scrutinised regarding their structure, which sheds some light on its interdependency and interconnectedness with part of speech semantics as well as emphasis. The data is quantified in terms of grammatical as well as information distribution-related issues. This analysis results in a detailed description of two major categories of the Old English swa simile depending on the number of verbalised components, their positioning, and grammatical expression; it also briefly touches upon the chronological peculiarities of the concerned constructions as well as the comparison with other means of figurative similarity expression in Old English. The analysis is carried out on material that has never been studied before.
\end{abstract}

KEY WORDS: Old English, simile, tenor, vehicle, comparison marker, structure

\section{Introduction.}

Simile has never attracted as widespread an interest as metaphor in language studies, let alone Medieval simile. When referring to the research of Middle English simile structure conducted by Nevanlinna (1993), it would hardly be possible to mention any investigation of earlier simile constructions. However, there have been some sporadic instances of simile analysis as a part of Old English comparative clauses or dative case functioning studies (Baker (2012), Fisher (1992), Gergel (2008), McLaughlin (1983), Merritt (2013), Mitchell (1985)). The semantic features of simile as a stylistic figure in certain literary works attracted the attention of Margolis (1957), who draws a comparison between simile and related devices; as do Walker (2016), Beardsley (1981), Dawes (1998), Tyler (2006); while Amodio (2014) and Stodnick (2012) touch upon similes when analysing Old English translations and adaptations of Latin texts. These works, however, are too few in number as well as too haphazardly related to afford a robust and reliable basis for the discussion of the phenomenon of the Old English simile. Even if one uses the tools for automatic selection, a very detailed analysis of simile in individual texts will not give us the desired generalizations in tendencies or regularities. In other words, sporadic and/or text/author-bound simile research will provide too little data. One will either miss phenomena or have too few examples to acquire adequate significance. This is why a corpus approach is called for. In order to provide an empirically adequate account of Old English simile with the swa component, I scrutinized a representative, reliable and freely accessible corpus of Old English texts, employing the method of continuous sampling. The online database DOE Web Corpus contains at least one copy of every surviving Old English text while providing the tools for automatic selection. Therefore, every recorded Old English simile with the swa component was subjected to analysis. The entire sampled material consists of 493 units and should be considered exhaustive. There are several reasons why one would want to know how Old English simile functioned more than a millennium ago. The first is related to the importance of shedding some light on previously unknown facts, be they historical, social or linguistic. It takes a linguist to find the rules, investigate how they operate(d) and then provide a description of a particular system which will contribute to the proper grammatical description of the whole language. In order to make a complete and informative language description, we should answer the major diachronic questions on how everything changed in English over time. To do so, we need to be able to explain the synchronic states of the system's smallest constituents. That means we must focus on its constituent elements' states in every language period to eventually get a bigger picture of the issue in question. In this case, the particular issue is simile. Another reason to study the development of simile is that it is a powerful tool that can reveal fascinating linguacultural 
information about how its users saw the world, showing their believes, priorities, associations and states of mind.

In this paper, I treat simile from a relevance theory prospective, considering it a kind of comparison demanding a figurative interpretation, semantically being close to metaphor while syntactically, at times, coinciding with a literal comparison. For this reason, I will employ terminology traditionally, used by researchers who regard simile as a trope, a theoretical explanation of which is inevitably intersubstitutable with that of metaphor ${ }^{1}$ (Fauconnier and Turner (2002); Gentner (1983); Gentner and Bowdle (2008); Glucksberg (2008); Glucksberg and Haught (2006); Glucksberg and Keysar (1990); Glucksberg and McGlone (1999); Grice (1989); Lakoff (2008); Lakoff and Johnson (2003); Lakoff and Turner (1989); Searle (1993); Turner (1996)), with the focus being made on simile only. This paper seeks to address the ways in which one Old English simile type was formed and used in the $9^{\text {th }}-11^{\text {th }}$ centuries. The structures in focus are similes marked by the ancestor of the Modern English so and as, a comparison marker swa (swa) or swa ... swa ..., as well as ealswa, which seems to be a rather neglected area in the field of linguistic studies of medieval English. Old English swa was a multifunctional lexeme: It could serve as a conjunction, a pronoun, an adverb, or an adposition. The grammatical polyfunctionality of swa received its due attention in Ericson (1932) and Schleburg (2003), while Niilo Peltola (1959) attempted to describe its identifying function, but only remotely and patchily connected his studies with the concept of a figurative comparison. So, this paper calls into question structural features of one of the predecessors of present-day English similes - Old English simile with the swa marker. Swa in Old English similes tends to be fully reduplicated, contributing to the expressiveness and figurativeness of the expression, as in the simile taken from the $11^{\text {th }}$ century Paris Psalter, where deep waters are compared to a robe, given by God to the earth during the creation of the world:

(1) He nywolnessa neoðan swa swa ryfte 〈him> to gewade woruhte swylce; $\mathrm{He}$ abyss below like cloak for them garment made alike; standað ofer mannum muntas on waterum. stand over men mountains in water. (PPs A5 [0819 (103.7)])

'He also created the depths beneath like a garment; The mountains in the waters stand above men.'

Occasionally the Old English swa was intensified with eal-, producing another equivalent for the simile marker ealswa (sometimes spelt eallswa), which was used in the same function alongside a single or a doubled swa, as in the $9^{\text {th }}$ century Martyrology, which describes the behaviour of demons through simile:

(2) Hwilum $\underline{\text { hi}}$ hine bylgedon on swa fearras ond $\underline{\text { Juton }}$ eallswa wulfas. Sometimes they him bellowed at like bulls and howled like wolves. (PPs A5 [0819 (103.7)])

'Sometimes they bellowed at him like bulls and howled like wolves'.

The above-mentioned variations of $s w a$ as a simile marker were used unevenly in Old English, showing a marked tendency: 324 examples of a doubled swa; 157 ones of a non-reduplicated swa; and merely 12 examples of ealswa were sampled. The preference of one over the others is described by specialised literature as a matter of a personal choice (Mitchell, 1985, p. 652), which can actually be illustrated by example (2), where the homogeneous similes employ two different markers with no apparent structural or semantic difference: bylgedon swa fearras 'bellowed like bulls' and ðuton eallswa wulfas 'howled like wolves'. However, the material provides grounds to argue that the choice of a single or doubled swa as well as ealswa might have been motivated by certain grammatical as well as information flow-related environments. It should be noted that, in this paper, the Anglo-Saxon simile is not understood as a purely autochthonous phenomenon. It is rather regarded as a symptomatic reflection of the symbiosis of native mentality with the ongoing cultural forces of Christianisation,

\footnotetext{
1 Talking about the constituents of simile, I will use the terms traditionally employed by the linguists terminologically following I. A. Richards (1936), who introduced technical terms to describe metaphor: the tenor (primum comparandum) and the vehicle (secundum comparatum), which later were expanded into the tenor, the vehicle and the ground (tertium comparationis), with the tenor being the subject of escribed attributes, the vehicle - the object whose attributes are borrowed, and the ground - a common salient feature of the tenor and the vehicle. Thus, in the simile Her lips are red like roses, the tenor is lips, the vehicle is roses while the ground is red.
} 
which inevitably presupposes the influence of Latin, as many Old English manuscripts are translations or adaptations of Latin texts. I assume it is the synergy of the three that contributed greatly to shaping the Anglo-Saxons and the language they spoke. The primary restriction on this study is that, although it involves data from the largest available corpus, it only includes written materials which have survived. To put it differently, we have to deal with what we have, not being ever able to acquire additional data. On the other hand, the texts sampled in the corpus are real texts used by Anglo-Saxons for communicative purposes, which means that they represent real structures and the functioning of a real language as it was naturally used by native speakers. Another problematic issue is the fact that there are a lot of translated texts from Latin originals within the corpus. However, the investigations of Pitt (Pitt, 1971, p. XXIX), Dekker (2005), Komen (Komen, 2013, p. 15) as well as Amodio (Amodio, 2014, pp. 221-222) have shown that Old English instances of simile do not always have a matching simile construction in the Latin source text, which is why I argue that the similes retrieved from the abovementioned corpus are fairly representative of Old English.

\section{The structure of the Old English simile with the swa component.}

The constructions under consideration display several types of syntactic patterns, making it indispensable to classify them according to certain criteria so that no relevant features are missed. Old English is well-known to have had a relatively free word order, which influenced the way simile constituents were organized into a construction. The terms "open simile" and "closed simile" have gained general acceptance in the simile semantics domain (Margolis (1957); Beardsley (1981); Dawes (1998); Walker (2016)). I will adopt this terminology to distinguish between the structural types of Old English simile as a useful tool to mark the grammatical non-expression/expression of the ground of simile, which will help to organize all the structures of similes with the swa component into a consistent paradigm. The criteria for the offered structural classification are: 1) the number of the simile components explicated in the surface structure: three (tenor, vehicle, and a comparison marker) or all four (tenor, vehicle, comparison marker, and a common salient feature shared by the tenor and the vehicle); 2) their grammatical expression; 3) their positioning. The observation of the electronically available OE corpus allows us, in fact, to single out two specific categories in swa similes:

a) In the first category, a tenor is expressed by a lexeme, basically showing a pre-positional use of a tenor in a tenor-vehicle pair. It generally seems to have been natural for Old English similes, for example:

(3) Đar gesegon cristne men heora sawle fleogan to heofonum

There saw Christian men their souls fly to heavens
swa swa culfran, ond hi waron seofon siðum hwittran
like

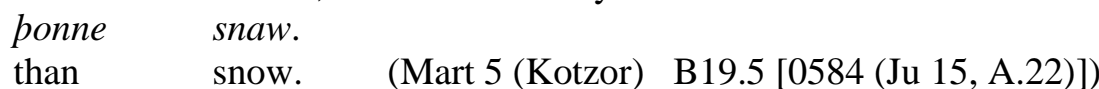

'There Christians saw their souls fly to heaven just like doves, and they were seven times whiter than snow.' However, there are eight registered exceptions, taken from 11th century texts (five of them - from Cambridge Psalter, one - from the Regius Psalter, another one - from the Canticles of the Salisbury Psalter, and one more - from Aelfric's Homilies) where the vehicle precedes the tenor, as in the example sampled from Regius Psalter:

$\begin{array}{llllllll}\text { (4) } \begin{array}{l}\text { Soplice } \\ \text { But }\end{array} & \frac{\text { swa swa }}{\text { like }} & \frac{\text { deaf }}{\text { deaf }} & \frac{\text { na ic }}{\text { not I }} \frac{\text { gehyrde }}{\text { heard }} & \frac{\text { swa swa }}{\text { like }} & \frac{\text { dumb }}{\text { dumb }} & \frac{\text { se na }}{\text { that not }} & \frac{\text { atiende }}{\text { opened }} \\ \frac{\text { muð }}{\text { mouth }} & \text { his. } & \text { his. } & \text { (PsGID (Roeder) C7.9 } & [0565(37.14)])\end{array}$

'But like deaf did not I hear, like dumb did not open this mouth.'

This fact can hardly be related to any possible dialectal variation, however, because the vast majority of swa similes, retrieved from Cambridge Psalter (35 cases) or from Aelfric's Homilies (81cases) witness the usual tenor-vehicle order.

b) The second category is where both a tenor and a vehicle are expressed by clauses, basically showing a post-positional use of a tenor in a tenor-vehicle pair. This type of simile is mostly a kind of a figurative analogy where a tenor and a vehicle do not only nominate the referent (in contrast to the previous group), they provide relevant information about it, which is vital for the juxtaposition of different notions. It is worth mentioning that swa is the only Old English simile marker that allows for 
the juxtaposition of two processes, where the first one indicates a vehicle, while the second includes, for example, a tenor:

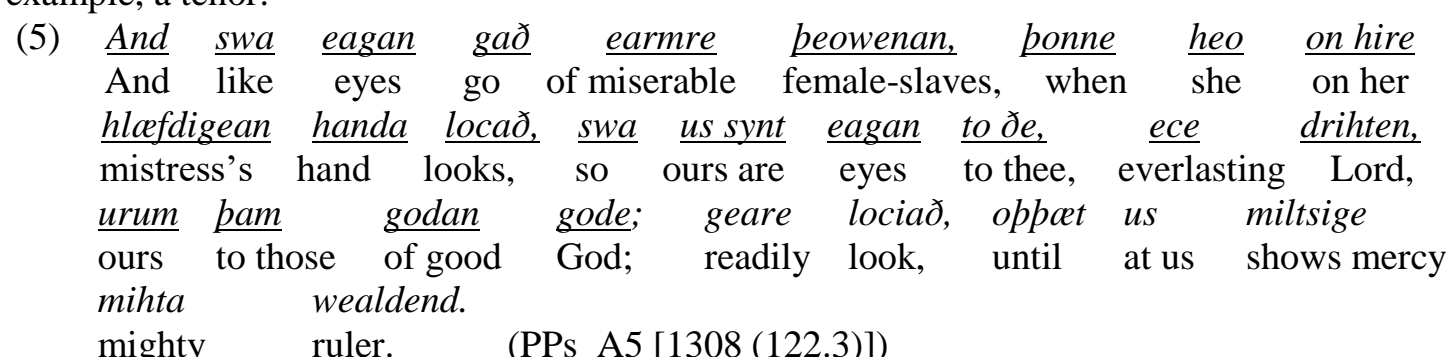

'As the eyes of slaves look to the hand of their master, as the eyes of a female slave look to the hand of her mistress, so our eyes look to the Lord our God, till he shows us his mercy.'

Taken from the $11^{\text {th }}$ century Paris Psalter, the simile teaches how to be modest, submissive, and meek by describing the look one should have addressing God, where the vehicle (slave's look) proceeds the tenor (our look). These two categories of swa simile allow for several structural options, the peculiarities of which I am going to highlight in the following classification.

1.1. Old English swa simile with the tenor expressed by a lexeme.

Old English similes with the swa component usually start with a tenor and can be either open (when they do not lexicalise a salient feature: subtypes of 1.1.1.) or closed (when it lexicalises a salient feature: subtypes of 1.1.2.).

1.1.1. Open Old English swa simile with the tenor expressed by a lexeme. This structural type of simile is comprised of two subtypes: those which express a) the similarity of a certain quality $(\mathrm{N} /$ Pron + swa swa $+\mathrm{N} / \mathrm{NP})$ and b) the similarity of the manner of action $(\mathrm{V}+$ swa swa + clause).

a) The similarity of a certain quality. Being open, the first subtype coincides with the structure $\mathrm{N} /$ Pron +swa swa $+\mathrm{N} / \mathrm{NP}$, consisting of three elements: the first component can be either a noun or a pronoun representing the tenor of the simile, the second component is a comparison marker swa (fully duplicated 64 times out of 77) and the third component is another noun or a noun phrase representing the vehicle, for example:

(6) For $i$ hi fornimð hellefyr swaswa ceaf, and heora wyrtruma bið For that them consume hellfire like chaff, and their roots become swaswa windige ysla.

like windy ashes. (ÆCHom II, 21 B1.2.24 [0075 (184.147)])

'Therefore shall the fire of hell consume them as chaff, and their root shall be like windy ashes.'

In the 11th century Aelfric's Homily, the wyrtruma 'roots' are compared to ysla 'ashes' without the explication of the salient feature.

Sometimes, the basic construction is extended by a clause which specifies the vehicle but cannot be regarded as an explicit commonly shared feature since it is not semantically specific enough to derive this property. It corresponds to the structure N / Pron +swa swa + N / NP + clause, for example:

(7) Nellad ge beon swaswa hors \& mul on pam nys andgyt Not will you be like horse and mule on those false understanding,

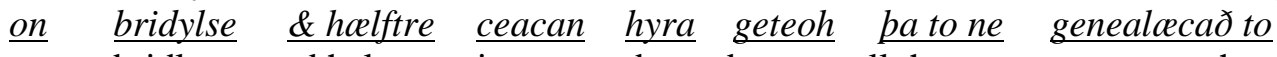
on bridles and halter jaws dependant, pull those to approach to $\underline{\partial e}$. you. (PsGlC (Wildhagen) C7.1 [0424 (31.9)])

'Do not you be like a horse, or mule, which have no understanding, they must be controlled with a bridle and bit in the jaws to come to you.'

In order to say that sinners will not follow Christian principles of their own accord, they constantly must be coerced by means of compulsion and restraint, the simile is used in the 11-th century Cambridge Psalter, in which the vehicles hors \& mul 'horse and mule' are specified by the clauses expressing the beasts' lack of understanding and need to be controlled. However, the salient feature in question (wild / fierce / incapable of thinking / irrational) is not mentioned and has to be deduced; so, in spite of an extended specification of the type of an animal, the simile cannot be considered a closed one. 
This structural type of a swa simile performs a descriptive function where the similarity of a certain quality is meant, for instance "roots" will have some quality of "ashes" (6) or sinners will have some quality of animals (7).

b) The similarity of the manner of action. Being open, this subtype consists of three elements: $\mathrm{V}+$ swa swa + clause. The first component is a verb representing the tenor of the simile, the second component is the comparison marker swa swa, and the third component is a clause representing the vehicle, for example:

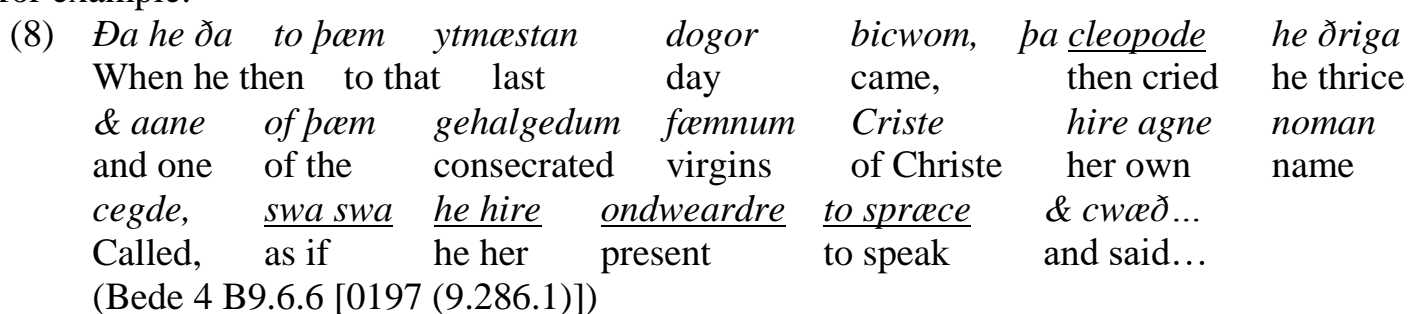

'And when he came to his last day, he thrice cried out and called to one of the consecrated virgins of Christ by her own name, as if she were present and he was speaking to her...'

In the provided example from the 9th century translation of Venerable Bede's writing, in which a dying man sees someone who is not present, there are no objects or entities being compared. However, the manner of the action (calling) is specified by the clause which describes the way in which the concerned action was performed.

\subsubsection{Closed Old English swa simile with the tenor expressed by a lexeme.}

If a simile of this structural type is closed, its composition is complicated by additional lexemes or phrases which verbalise the concept that makes the simile closed (further in the text they are typed in bold). Three subtypes of the closed Old English swa simile can be singled out depending on the grammatical expression of the ground that represents a commonly shared feature. Typically, they are the extensions or modifications of the basic open structures N/Pron $+s w a s w a+\mathrm{N} / \mathrm{NP}$ and V $+s w a$ swa + clause (described in 1.1.1.), showing the similarity of quality and the similarity of manner correspondingly.

1.1.2.1. Closed Old English swa simile with the tenor expressed by a lexeme in which the ground is expressed by an adjective.

This structural subtype is a modification of the basic structure N/Pron $+s w a s w a+\mathrm{N} / \mathrm{NP}$. The adjective is generally placed between the tenor and the comparative marker sometimes employing another $s w a$, thus making a structure N / Pron + (swa) + Adj + swa $(s w a)+\mathrm{N} / \mathrm{NP}$ (which generally corresponds to modern as ...as... simile), as in this 11th century Homily describing an angel:

\begin{tabular}{|c|c|c|c|c|c|c|}
\hline $\begin{array}{l}\text {...pas engles } \\
\text {..that angle's } \\
\text { swa egeslic }\end{array}$ & $\begin{array}{l}\begin{array}{c}\text { ansyn, } \\
\text { face, }\end{array} \\
\text { swa swa }\end{array}$ & $\begin{array}{l}\text { cwaed } \\
\text { said } \\
\text { ligetu, }\end{array}$ & $\begin{array}{l}\text { se Godspellere, } \\
\text { the Gospel, } \\
\text { and his hragl }\end{array}$ & $\begin{array}{r}\text { waes } \\
\text { was } \\
\text { waron } \\
\end{array}$ & $\begin{array}{l}\text { swa beorht } \\
\text { so bright } \\
\text { swa hwit }\end{array}$ & $\begin{array}{l}t \quad \frac{\text { and }}{\text { and }} \\
\text { swa snaw }\end{array}$ \\
\hline
\end{tabular}

(HomS 25 B3.2.25 [0077 (243)])

'...that Angel's face, the Gospel said, was as bright and as awesome as lightning and his clothes were as white as snow.'

In contrast with the majority of swa similes in Old English, which show a marked tendency to have the comparison marker fully reduplicated, this structural subtype acts in the opposite way: out of 77 concerned similes only $25(32 \%)$ have a doubled swa as a comparison marker. Moreover, those structures which have a doubled swa as a comparison marker tend not to employ another swa before the adjective serving as the ground of a simile. Out of those 25 that employ a doubled swa, the material shows 10 constructions (40\%) organised as swa ...swa swa ... as the first simile in (9), and 15 ones (60\%) that lack the additional swa element before the adjective as in the second simile in (9).

1.1.2.2. Closed Old English swa simile with the tenor expressed by a lexeme in which the ground is expressed by a verb.

Closed Old English swa similes in which the ground is expressed by a verb can be categorized into three subgroups mainly due to the positioning of the verb within the construction.

a) In the majority of cases, the verb is placed between the tenor and the comparison marker often repeated after the vehicle: $\mathrm{N}+\mathbf{V}+\operatorname{swa} s w a+\mathrm{N}(+\mathbf{V})$. The repetition of the verbalized ground stresses 
DOI: https://doi.org/10.37708/ezs.swu.bg.v19i3.2

the fact that the referents represented by the tenor and the vehicle perform the same action, as in the $10^{\text {th }}$ century Boethius:

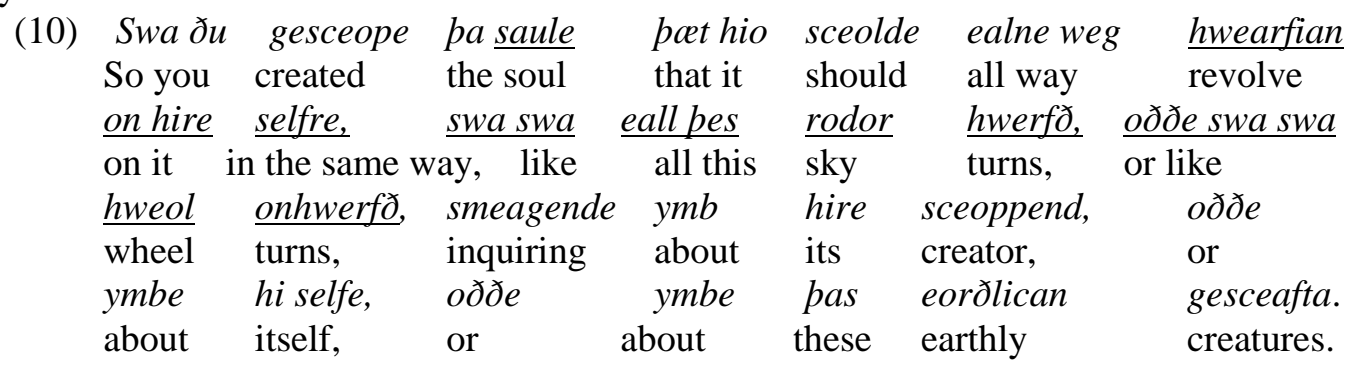

(Bo B9.3.2 [1009 (33.81.25)])

'In such a way you created the soul that it must always turn towards itself, as all this sky turns, or as a wheel turns round, inquiring about its maker, or about itself, or about these earthly creatures.'

To describe the uneasy nature of the human soul, Boethius repeats the verb hwearfian 'wander, revolve' three times to equal the constant movement of a soul, a wheel, and, as it was believed at the time, permanent turning of the sky.

b) Out of 243 swa similes employing a verb as a ground, 38 (about 15,6\%) place it before the noun representing the tenor, which corresponds to the structure $V+\mathrm{N}+\operatorname{swa} s w a+\mathrm{N}$, as in the early $11^{\text {th }}$ century Forty Soldiers by Aelfric:
(11) Da grimetede sewalhreowa swa swa gradigleo, and het hi gebringan Then raged the cruel like greedy lion, and bade them brought gebundene on cwearterne, bound to dungeon... (ÆLS (Forty Soldiers) B1.3.12 [0022 (62)])

'Then raged the cruel one like a greedy lion and bade that they should be brought bound into the dungeon.'

c) The least numerous is the structure in which the verb occurs in the final position of a simile which corresponds to $\mathrm{N}+$ swa $s w a+\mathrm{N}+\boldsymbol{V}$ :

(12) And icfor cristes lufe forlat eow ealle, and middaneardlice lustas And I for Christ's love abandoned you all, and world's lusts $\frac{\text { swa swa }}{\text { like }} \frac{\text { meox }}{\text { dung }} \frac{\text { forseah. }}{\text { despised. }} \quad$ (ÆLS (Eugenia) B1.3. [0075 (240)])

'And I, for Christ's love, abandoned you all, and the lusts of the world as dung I despised.'

In the provided example from the $11^{\text {th }}$ century Aelfric's Lives of Saints, the virgin Eugenia addresses her parents explaining her priorities. The verb forseah, 'despise', is placed in the final position of the simile, which occurs in 10 cases out of 243 . That is, in only $4 \%$ of the sample.

It is worth mentioning that the similes in question, which employed the ealswa marker, were registered within this subgroup only. The examples are too few to put forward a plausible hypothesis, but it seems that the productivity of ealswa is directly connected to the presence of a verbal element in the structure.

1.1.2.3. Closed Old English swa simile with the tenor expressed by a lexeme in which the ground is expressed by a verb and an adverbial adjunct.

In such similes, the verb, which serves as a ground, is specified by an adverbial adjunct. The latter is always expressed by an adverb of manner, for example:

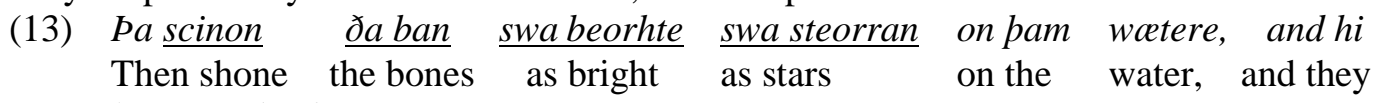
Jas wundrodon.

there wondered. $\quad$ (ÆLS (Forty Soldiers) B1.3.12 [0084 (269)])

'Then shone the bones as brightly as stars in the water, and they wondered thereat.'

In the $11^{\text {th }}$ century Lives of Saints (Forty Soldiers), the bones of dead, God loving soldiers are compared to the stars on the ground. They shine equally brightly. Though there are only eight similes of this kind, all of them demonstrate one structural pattern: $\mathbf{V}+\mathrm{N}+s w a+\mathbf{A d v}+s w a+\mathrm{N}$. None of those similes employed a doubled swa as a comparison marker, splitting the latter into two single swa with an adverb in between, which corresponds to modern structure as+adv+as.

1.2. Old English swa simile with its tenor and vehicle expressed by clauses. 
These structures represent a special kind of Old English simile in which both a tenor and a vehicle describe a certain situation and are expressed by clauses, as in the $9^{\text {th }}$ century translation of Bede's Historia Ecclesiastica about the suffering of the Britons:

$(14)$

\begin{tabular}{|c|c|c|c|c|c|c|}
\hline $\begin{array}{l}\text { Fordon } \\
\text { Therefore }\end{array}$ & $\frac{\text { swa swa }}{\text { like }}$ & $\frac{\text { sceap }}{\text { sheep }}$ & $\frac{\text { from }}{\text { by }}$ & $\frac{\text { wulfum }}{\text { wolves }}$ & $\frac{\& \text { wildeorum }}{\text { and wild-beasts }}$ & $\frac{\text { beod }}{\text { are }}$ \\
\hline & swa $b a$ & earman & ceaster & ran to & oslitene & vaerc \\
\hline & & & & & & jere \\
\hline & $\begin{array}{l}\text { feondum } \\
\text { foes, }\end{array}$ & $\begin{array}{c}\& \\
\text { and }\end{array}$ & $\begin{array}{l}\text { heor } \\
\text { their } \mathrm{p}\end{array}$ & $\begin{array}{l}\text { ehtum } \\
\text { essions }\end{array}$ & $\begin{array}{l}\text { benemde } \& \text { to hut } \\
\text { collected and to } \mathrm{h}\end{array}$ & lunger \\
\hline
\end{tabular}
gesette.

set. $\quad$ (Bede $1 \quad$ B9.6.3 [0147 (9.46.22)])

'Just like sheep are destroyed by wolves and wild beasts, so the poor townsmen were rent and destroyed by their foes, being stripped of their possessions and left to starve'

The similes under consideration can be categorized into two subtypes: a) similes in which tenors precede vehicles; b) similes in which vehicles precede tenors.

1.2.1. Old English swa simile with its tenor and vehicle expressed by clauses in which a tenor clause precedes a vehicle clause.

All similes of this subtype employ a fully reduplicated comparison marker and correspond to the structure clause+swa swa+clause, for example:

$$
\begin{aligned}
& \begin{array}{llllll}
\text {...on ðam fleoðfugelas, } & \text { swa swa } & \text { fixas swymmad } & \text { on watere. } & \text { Ne mihte } \\
\text {...in it } & \text { fly birds, } & \text { like } & \text { fish swim } & \text { in water. } & \text { Not could }
\end{array} \\
& \text { heora nanfleon, nare seo lyft ðe hi berð... } \\
& \text { they none fly, was not that air that them bears... } \\
& \text { (ÆTemp B1.9.4 [0218 (10.4)]) }
\end{aligned}
$$

'In it (air) birds fly just like fish swim in water. None of them would be able to fly were it not for the air that supports them.'

Describing the physical properties of air, Aelfric resorts to the comparison of two propositions in his De Temporibus Anni: birds flying in the air and fish swimming in the water, on the grounds that both are supported by a certain substance.

1.2.2. Old English swa simile with its tenor and vehicle expressed by clauses in which a vehicle clause precedes a tenor clause.

Old English swa similes with their tenors and vehicles expressed by clauses, in which vehicle clauses precede tenor clauses (Swa swa+clause $+s w a+$ clause), were used more often than the previous subtype. Displaying a rather atypical characteristic of Old English similes, they always start with a vehicle, for example:

$$
\begin{aligned}
& \text { (16) <Rece> hi gelicast ricene geteoriað; swaframfyre weaxflowed } \\
& \text { To-smoke them most-like mighty perish; like by fire wax flows; } \\
& \text { andmylteð, swa bafyrenfullan frecneforweordað; habbað } \\
& \text { and melts } \underline{\text { so }} \text { the wicked horrible perish have }
\end{aligned}
$$

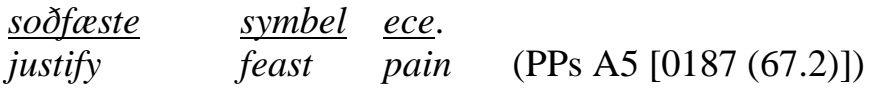

'May you blow them away like smoke - as wax melts before the fire, may the horrible wicked perish, have them just feast of pain.'

In the $11^{\text {th }}$ century Paris Psalter, the perishing of sinners is compared to the melting of wax, with more established information for an average Anglo-Saxon (wax melting) preceding less established information (Christian ideology).

An interesting observation can be made here in terms of the positioning of a reduplicated comparison marker: It is found reduplicated 35 times out of 45 , and when it is doubled it always occurs before the vehicle. In other words, if a simile starts with a vehicle and employs the reduplicated swa swa, the latter will occur in the beginning of the whole structure with another swa before the tenor, as in $11^{\text {th }}$ century Aelfric's Lives of Saints:

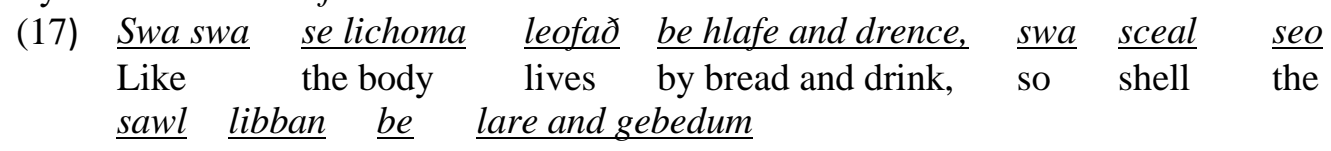


soul live by doctrine and prayers. (ÆLS (Pr Moses) B1.3.14 [0025 (89)])

'As the body lives by bread and drink, so shall the soul live by doctrine and prayers.'

In the provided example (17), the body living by food serves as a vehicle since it contains standard prototypical information about the necessity of nourishment. Being placed at the beginning of the sentence, it takes a doubled $s w a$, otherwise placed in the middle of the construction.

Statistics on data regarding Old English swa similes are presented in Table 1.

Table 1. Structural types of the Old English simile of equality containing a comparison marker swa.

\begin{tabular}{|c|c|}
\hline $\begin{array}{l}\text { Structural Type } \\
\end{array}$ & Number \\
\hline 1.1. Old English swa simile with the tenor expressed by a lexeme. & 429 \\
\hline 1.1.1. Open Old English swa simile with the tenor expressed by a lexeme. & 109 \\
\hline a) $\quad \mathrm{N} /$ Pron + swa swa $+\mathrm{N} / \mathrm{NP}$ & 95 \\
\hline $\mathrm{V}+$ swa swa + clause & 14 \\
\hline 1.1.2. Closed Old English swa simile with the tenor expressed by a lexeme. & 320 \\
\hline 1.1.2.1. N / Pron + (swa) + Adj + swa $(s w a)+\mathrm{N} / \mathrm{NP}$ & 77 \\
\hline 1.1 .2 .2$. & 235 \\
\hline a) $\mathrm{N}+\mathrm{V}+$ swa $s w a+\mathrm{N}$ & 195 \\
\hline b) $\mathrm{V}+\mathrm{N}+$ swa $s w a+\mathrm{N}$ & 30 \\
\hline c) $\mathrm{N}+$ swa $s w a+\mathrm{N}+\mathbf{V}$ & 10 \\
\hline 1.1.2.3. $\mathbf{V}+\mathrm{N}+s w a+\mathbf{A d v}+s w a+\mathrm{N}$ & 8 \\
\hline 1.2. Old English swa simile with the tenor expressed by a clause. & 64 \\
\hline 1.2.1. clause + swa swa+clause & 19 \\
\hline 1.2.2. Swa swa+clause + swa + clause & 45 \\
\hline Total & 493 \\
\hline
\end{tabular}

Reading the table vertically, we can see the whole scope of structural options of swa simile in Old English and their total number, while a horizontal reading of the table shows the productivity of the singled out structural types and subtypes.

What we can conclude from the statistical data in Table 1 is that the productivity of swa simile is boosted by the presence of a verbal element in the structure. Out of 493 similes whose elements are expressed by lexemes, 257 (52\%) contain a verb freely placed within the construction either as a tenor or as a ground. The number does not seem to be striking at first, but if we compare the statistical data of Old English similes with copulative lice, we will see that the preference in a verbal colligation is much stronger for the swa constituent than for the lice constituent. The similes with a split swa component (1.1.2.1. and 1.1.2.3.) show a strong tendency not to use a reduplicated swa marker (only 10 out of 85 similes $(1,2 \%)$, which employ an adjectival or adverbial element for their grounds, use both split and reduplicated markers swa...swa swa). It should be noted that only adjectives and adverbs are capable of sometimes splitting the reduplicated swa swa marker into two single swa markers, with the first being placed before the ground serving as a parameter marker and the second being placed before the vehicle serving as a standard marker. In other words, the first swa introduces the salient feature while the second swa nominates the standard, a typical bearer of that feature. The use of a single or a doubled swa was touched upon in Peltola (1959: 170), who primarily connected it with the different origins of adjectival and substantival swa-phrases. I am rather inclined to think that it is not an originrelated issue but a part of speech and semantics motivated phenomenon since, out of all parts of speech, only adjectives and adverbs (words with intrinsic indication of quality) tend to avoid the repetition of the swa element. This even distribution of the swa component between the ground and the vehicle seems to have structurally balanced the construction which was directly connected with emphasis. It looks like the balanced placement of swa alongside the explicated expression of a certain kind of quality (adjective or adverb) was emphatic enough, and additional emphasis, caused by the reduplication, would be pleonastic.

There is another argument against a purely grammatical origin-related motivation of swa reduplication. I would like to bring some attention to one piece of evidence, which might seem marginal 
at first, but, in fact, can be a significant one. The point is that, though swa element is found either single or doubled in all singled-out structures (except for it is always single if split by an adverb), it shows a very strong tendency to be reduplicated before the vehicle. In all 481 studied examples, the reduplicated $s w a$, if it is so, is found before the vehicle and never before the tenor. More than that, it is clearly seen when simile elements are reordered: If the vehicle is placed in the initial position of the construction, swa swa occurs in the initial position as well (see example (4) or all the examples of the subtype $S w a$ swa+clause+swa+clause). The same reasoning goes for the ealswa marker: whenever it is used, it always occurs before the vehicle and never before the tenor. More than that, if it is placed initially within the simile, the vehicle is reordered into the initial position as well. In this paper, I am not touching upon the reason-consequence connections of what causes what: whether it is a structural-dependent vehicle fronting when the initial placement of the reduplicated swa or ealswa triggers a tenor-vehicle inversion, or if it is a conscious manipulation of word order to convey emphasis so that a reader understood what is focused on. However, within the sampled material, it seems obvious that the reduplication of swa is more connected with semantics and emphasis than with the origin of the structure. The conjecture that it might be related to a particular author's style should be ruled out as well because the concerned structures are found in texts by different authors / translators in different styles (from proverbs to religious writings) in different centuries. Whatever the thoughts on the matter, this issue should be explored further in other research. The numbers from Table 1 clearly illustrate the marginal character of figurative comparisons employing the juxtaposition of two situations expressed by clauses, which constitute only $13 \%$ of the analysed material. However, if compared to the similes, whose elements are expressed by lexemes, the clausal swa similes display a tendency to place their vehicle in preposition regarding the tenor more than 6 times as often ( 7 against 45 items). Without elaborating on the importance of word order within similes (which is not the focus of this paper), it should be noted that the post-positional use of a tenor in a tenor-vehicle pair in this kind of simile reflects the Old English tendency to comply with the Principle of Natural Information Flow, where a more established material precedes less established information (Komen, 2013, p. 8). The explanation for why this analogy-type simile complies with the Principle of Natural Information Flow - while others typically do not - might be connected with the "informational" rather than nominal character of the two simile constituents (tenor and vehicle). The point is that not only does this particular kind of simile name a tenor and a vehicle, it always provides certain information about their states or activities that should be similar in some way from the speaker's point of view.

\section{Chronological characteristics of Old English swa simile.}

The chronological distribution of Old English manuscripts still remains an issue of speculation in many cases, contributing to a relative uncertainty in terms of the distribution of the structural types of simile through the centuries. Unfortunately, the biggest corpora of Old English, from which the sampling was retrieved, do not provide the exact century of the manuscript's composition: DOEC divides Old English into two periods only (early and late); the Helsinki Corpus is more specific in this respect, but it solely contains texts from 950-1050. Such a situation leaves us with the mere option to obtain information about a manuscripts' composition date from other sources, as well as inference. The subdivision into two periods only would be too rough of an approach for a study like this. So, since the reference of a manuscript to a certain century is not always perfectly established, some logic had to be imposed on the process of dealing with the disputed texts. Thus, the data from all available informative sources was compared in order to attribute the most exact possible century for the manuscript in question. In the case of an attribution of a manuscript date to a period comprising more than one century, the latest century was chosen in order to represent the time when the text unquestionably existed. Statistics relating to the chronological distribution of the similes under analysis is shown in Table 2.

Table 2. The chronological appearance of the Old English simile of equality with a

$$
\text { comparison marker swa. }
$$

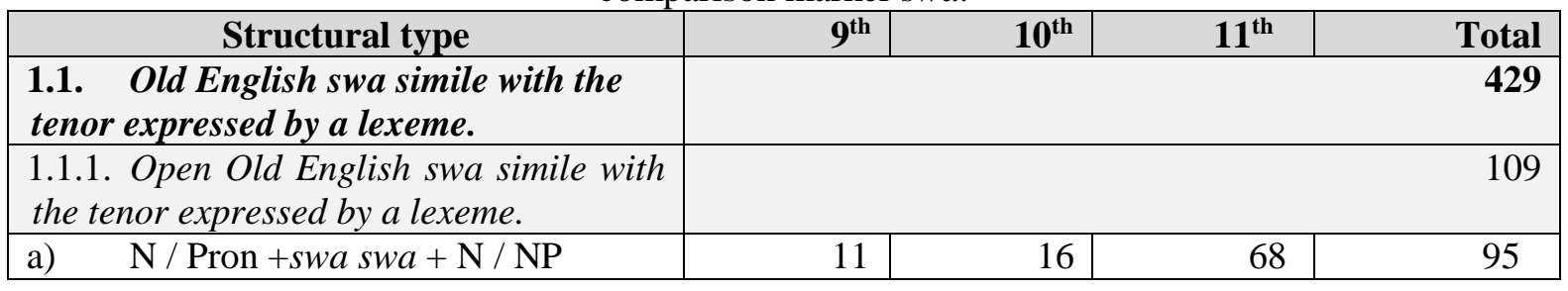


„ O R B IS L I N G UAR UM “, VOLUME 19, IS S UE 3

DOI: https://doi.org/10.37708/ezs.swu.bg.v19i3.2

\begin{tabular}{|c|c|c|c|c|}
\hline b) V + swa swa + clause & 3 & 3 & 8 & 14 \\
\hline $\begin{array}{l}\text { 1.1.2. Closed Old English swa simile with } \\
\text { the tenor expressed by a lexeme. }\end{array}$ & & & & 320 \\
\hline $\begin{array}{l}\text { 1.1.2.1. N / Pron + }(s w a)+\mathbf{A d j}+s w a \\
(s w a)+\mathrm{N} / \mathrm{NP}\end{array}$ & 5 & 20 & 52 & 77 \\
\hline 1.1 .2 .2 & & & & 235 \\
\hline a) $\quad \mathrm{N}+\mathrm{V}+$ swa $s w a+\mathrm{N}$ & 16 & 41 & 138 & 195 \\
\hline b) $\mathrm{V}+\mathrm{N}+$ swa $s w a+\mathrm{N}$ & 2 & 4 & 24 & 30 \\
\hline c) $\mathrm{N}+$ swa $s w a+\mathrm{N}+\mathrm{V}$ & 1 & 1 & 8 & 10 \\
\hline 1.1.2.3. $\mathrm{V}+\mathrm{N}+s w a+\mathrm{Adv}+s w a+\mathrm{N}$ & 1 & 1 & 6 & 8 \\
\hline $\begin{array}{l}\text { 1.2. Old English swa simile with the } \\
\text { tenor expressed by a clause. }\end{array}$ & & & & 64 \\
\hline 1.2.1. clause + swa swa + clause & 9 & 2 & 8 & 19 \\
\hline 1.2.2. Swa swa+clause + swa + clause & 2 & 9 & 34 & 45 \\
\hline Total & 50 & 97 & 346 & 493 \\
\hline
\end{tabular}

Reading the table horizontally, we can see the productivity of every structural type or subtype throughout the whole of the Old English period of their usage, while vertical interpretation of the table allows us to see the fruitfulness of a particular century in terms of swa simile appearance in the manuscripts. The increasing proliferation of the concerned constructions in the second half of the Old English period is quite predictable since this is the time when the majority of manuscripts appeared due to the active translation processes of Latin texts. However, their total absence at the beginning of the period is striking. It looks like before the $9^{\text {th }}$ century, Anglo-Saxons preferred employing other means of simile construction, with copulative lice, for example. The issue of single or doubled swa usage, briefly touched upon in the previous section, does not show any chronologically related dependence: Single swa usage gradually increases over the indicated centuries, though somewhat at a more even pace than a doubled swa.

\section{Conclusions.}

Being a very productive and polyfunctional lexeme in Old English, swa was much more often used outside of poetic comparisons, so not all the instances of Old English swa usage need to be automatically linked to simile. However, when it does appear as a simile comparison marker, we can observe a trend where the proportion of verb-constituent structural types markedly increases in comparison to Old English similes with a copulative lice as a comparison marker. Thus, the concerned simile was more productive in terms of describing similarity of manner of the action. Old English swa simile allows for the reordering of its constituents and grammatical expression, as well as the possibility of providing additional information to play an important role in this reordering. It shows a clear tendency to modify tenor-vehicle positioning depending on their "nominative" or "informational" character: if a tenor and a vehicle do not only nominate their referents but provide additional information about their actions or states, the inverted vehicle-tenor order is mainly observed. Otherwise, tenors are always placed prepositionally regarding the vehicles with only few exceptions. The issue of a (non)reduplicated swa element displays certain dependency on the word classes it relates to. The tendency to use a single swa marker over a doubled one is proven to have been characteristic of adjectives and adverbs more than of any other part of speech. This can be accounted for by the fact that, unlike nouns, pronouns or verbs, both adjectives and adverbs provide "extra information" about objects or actions concerning their quality. This intrinsic quality indication seems to have been substantial enough for the simile not to employ the reduplicated or strengthened by eal-swa element. It looks like the following principle was observed: The more precisely the quality is explicated, the less additional emphasis is needed. The analysis of the material revealed that it is very likely that the use of the reduplicated swa as well as ealswa is directly connected to the emphasis and general semantics of simile. They always occur in the adjacent position with the notion expressing a certain standard bearing the salient feature, regardless of the direct or inverted order of simile constituents. Never occurring before the tenor, a doubled swa and ealswa can serve as formal indicators of an immediately following them vehicle. Given the restrictions of this paper, there is enough research ahead of us, and there is a tempting perspective of studying Old English similes with other markers as well as investigating the behaviour of swa and ealswa outside similes. 


\section{REFERENCES:}

Amodio, M. C. (2014)

Beardsley, M. C. (1981).

Dawes, G. W.

(1998).

Healey, A., Holland, J.,

McDougall, D.,

McDougall, I., Xiang, $X$. (2009)

Ericson, E. (1932).

Fauconnier, G.; Turner,

M. (2002)

Fisher, O. (1992)

Gentner, D., \& Bowdle, B.

F. (2001)

Gentner, D. (1983)

Glucksberg, S.; Haught, C. (2006)

Glucksberg, S.; Keysar, B. (1990)

Glucksberg, S.; McGlone, M. S. (1999)

Glucksberg, S. (2008)

Grice, P. H. (1989)

Komen, E. R. (2013)

Lakoff, G., Johson, M. (1980)

Lakoff, G., Turner, M. (1989)

Lakoff, G. (2008)

Margolis, J. (1957)

Mitchell, B. (1985)

Peltola, N. (1959)

Pitt, A. M. (1971)

Schleburg, F. (2003)

Searle, J. R. (1993)

Turner, M, (1996)

Walker, M. A. (2016)
The Anglo-Saxon Literature Handbook. Wiley Blackwell. 432 p.

Aesthetics: Problems in the Philosophy of Criticism. Hackett Publishing, 614 p.

The Body in Question: Metaphor and Meaning in the Interpretation of Ephesians 5:21-33. Leiden : Brill, 264 p.

Dictionary of Old English Corpus in Electronic Form, TEI-P5 conformant version, 2009 Release. Compiled by. Toronto: DOE Project, University of Toronto. <http://www.doe.utoronto.ca> (04. 03. 2020).

The Use of Swa in Old English. Johns Hopkins University, 89 p.

The Way We Think: Conceptual Blending and the Mind's Hidden Complexities. NY: Basic Books, $464 \mathrm{p}$.

Syntax. In Norman Blake (ed), The Cambridge History of the English Language. Vol. II: 1066-1476. Cambridge University Press, p. 207-408

Convention, Form, and Figurative Language Processing. // Metaphor and Symbol, 16 (3-4), p. 223-247. http://doi.org/10.1080/10926488. 2001.9678896 Structure-Mapping: A Theoretical Framework for Analogy. // Cognitive Science, 7 (2), p. 155-170.

On the Relationship between Metaphor and Simile: When Comparison Fails. // Mind and Language, 21 (3), p. 360-378.

Understanding Metaphorical Comparisons: Beyond similarity. // Psychological Review, 97 (1), p. 3-18.

When Love is not a Journey: What Metaphors Mean. // Journal of Pragmatics, 31 (12), p. 1541-1558.

How Metaphors Create Categories Quickly. // The Cambridge Handbook of Metaphor and Thought. Cambridge: Cambridge University Press. p. 67-73. https://doi.org/10.1017/CBO9780511816802.006

Studies in the Way of Words. Harvard University Press, London, 394 p.

Finding Focus: a Study of the Historical Development of Focus in English. The Netherlands: LOT, $473 \mathrm{p}$.

Metaphors We Live By. The University of Chicago Press, 256 p.

More Than Cool Reason: A Field Guide to Poetic Metaphor. University of Chicago Press, London, $230 \mathrm{p}$.

The Neural Theory of Metaphor. // The Cambridge Handbook of Metaphor and Thought. Cambridge University Press, Cambridge, p. 17-38.

Notes on the Logic of Simile, Metaphor and Analogy. // American Speech, vol. 32. (3). Duke University Press, p. 186-189.

Old English Syntax. Vol 2. Oxford: Clarendon Press, 1080 p.

On The 'Identifying' Swa (Swa) Phrase In Old English. // Neuphilologische Mitteilungen, 60(2), p. 156-173. Retrieved February 27, 2020, from www.jstor.org/stable/43345292

An Edition of the Old English Prose Psalms of the Paris Psalter. University of Ottawa, 102 p.

Old English 'Swa'. // English and American Studies in German, p. 3-5. <https://www.degruyter.com/document/doi/10.1515/9783484431027.3/html> (04. 03. 2020)

Metaphor. // Metaphor and Thought. Cambridge University Press, Cambridge, p. 83-111.

The Literary Mind: The Origins of Thought and Language. Oxford University Press, Oxford, $196 \mathrm{p}$.

Automatically Inferring Implicit Properties in Similes. // Proceedings of NAACL-HLT. California: San Diego, p. 1223-1232. 